\title{
Characterisation of different hole transport materials as used in organic p-i-n solar cells
}

\author{
Steffen Pfuetzner ${ }^{a},{\text { Annette } \text { Petrich }^{a}, \text { Christine Malbrich }}^{c}, \operatorname{Jan}_{\text {Meiss }}{ }^{a}$, Maik Koch $^{a}$, Moritz K. \\ Riede $^{a}$, Martin Pfeiffer ${ }^{b}$, and Karl Leo ${ }^{a}$ \\ ${ }^{a}$ Institut für Angewandte Photophysik, Technische Universität Dresden, George-Bähr-Straße \\ 1, 01069 Dresden, Germany, http://www.iapp.de; \\ ${ }^{b}$ Heliatek GmbH, Liebigstraße 26, 01187 Dresden, Germany, http://www.heliatek.com; \\ ${ }^{c}$ Leibniz-Institut für Festkörper- und Werkstoffforschung Dresden, Helmholtzstraße 20, 01069 \\ Dresden, Germany
}

\begin{abstract}
To reach higher performances in organic solar cells, each layer has to be optimised with respect to its purpose. In the case of a p-i-n structured solar cell, the layers are the absorber system, the doped electron and hole transport layers, and the bottom and top contacts. This work focuses on the investigation and characterisation of the transparent hole transport materials PV-TPD, PV-TPDoM, Di-NPB, and MeO-Spiro-TPD, as used in organic p-i-n solar cells. The motivation is to replace the hole transport material MeO-TPD, which has been used so far despite its morphological instability at elevated temperatures, with an energetically and morphologically more suitable material. The hole transport materials were investigated for dopability, hole mobility, absorption, reflection, cyclic voltammetry, and glass transition temperature. Further specific material properties were determined with simplified structures, e.g. m-i-p diodes, and the standard solar cells, consisting of the fullerene $\mathrm{C}_{60}$ as acceptor and $\mathrm{ZnPc}$ as the donor material. The Di-NPB has turned out to be the best choice with respect to its intrinsic properties and device parameters. The deep lying HOMO, the high hole mobility of $\mu=1.9 \cdot 10^{-4} \mathrm{~cm}^{2} / \mathrm{Vs}$, the morphological stability of $T_{g}=158^{\circ} \mathrm{C}$, and the excellent results of the $\mathrm{C}_{60}: \mathrm{ZnPc}$ bulk heterojunction solar cell makes the Di-NPB highly suitable for replacement of the MeO-TPD in organic solar cells.
\end{abstract}

Keywords: organic solar cell, hole transport material, wide gap material, MeO-TPD, Di-NPB, p-i-n

\section{INTRODUCTION}

Contrary to the fossil fuels renewable energies like solar energy represent an inexhaustible energy source. Elegant approach to directly generate electric energy are photovoltaics, where silicon solar cells are well established. An alternative arises with the field of the organic solar cells, which have the potential for low production costs (e.g. screen printing, ${ }^{1}$ vacuum deposition, and spin coating). The organic dyes with the high absorption coefficients lead to thin active layers $(<100 \mathrm{~nm})$ and allow flexible devices ${ }^{2}$ and therefore innovative applications (e.g. in architecture and automobile industries).

The first organic solar cells with a power conversion efficiency of approximately $1 \%$ were made by Ching Tang ${ }^{3}$ in 1986. Good progress has been made since then, but it is still a challenge to obtain long-term stability, power conversion efficiency, and flexible encapsulation. ${ }^{4}$

The solar cells in this paper are based on the p-i-n structure concept. ${ }^{5,6}$ This means that the active absorbing part (i) is sandwiched by the doped transport layers for electrons (n) and holes (p) respectively. The controlled doping of the transport layers ${ }^{7,8}$ leads to high conductivities and ensures a mostly loss-free transport of electrons and holes towards the ITO or metal contacts, respectively. Additionally, the wide gap materials used as transport

Further author information: (Send correspondence to S.P.)

S.P.: E-mail: steffen.pfuetzner@iapp.de, Telephone: +49(0)351 46338773

K.L.: E-mail: karl.leo@app.de

Organic Optoelectronics and Photonics III, edited by Paul L. Heremans, Michele Muccini, Eric A. Meulenkamp, Proc. of SPIE Vol. 6999, 69991M, (2008) · 0277-786X/08/\$18 - doi: 10.1117/12.782412 




(a)



(b)

Figure 1. b) Stack of a p-i-n solar cell: the n- and p- transport layers can be varied for optimised field distribution. The incident light forms then a standing wave due to the high reflective metall contact. a) Energetic diagram of an ideal p-i-n solar cell: doped materials with wide band gaps form the n- and p- like regions. The transport layers behave like selective membranes due to the large gap to the intrinsic material.

materials are likewise excellent charge-carrier and exciton blocker ${ }^{9}$ as one can see in Fig. 1(b).

To obtain high power conversion efficiency one has to optimise the different parts of such a solar cell: firstly the photovoltaic active part for: (a) absorption, (b) open circuit voltage $V_{o c}$ and (c) photo current $j_{s c}$; secondly the transport layers for: (a) conductivity, (b) mobility, (c) thermal and morphological stability, (d) transparency and (e) compatible energy level alignment relative to the neighboring photovoltaic active layers. The properties of the transport layers also influence the fill factor and even the power conversion efficiency which is given by the formula

$$
\eta_{e f f}=F F \cdot \frac{j_{s c} V_{o c}}{I_{0}}
$$

$\mathrm{I}_{0}$ refers to the intensity of the light. Usually a standard AM1.5 (Air Mass) sun spectrum with $100 \mathrm{~mA} / \mathrm{cm}$ total power density is used.

Furthermore, the optical field distribution has to be optimised to the position of the photoactive absorber system. Due to the highly reflective metal contact, an optical maximum is formed and has to be placed where the absorption takes place. This can be achieved by varying the thicknesses of the transparent $\mathrm{n} / \mathrm{p}$-transport layers as it is shown in Figure 1(a). To avoid energy losses due to the transport of the charge carriers, the hole transport material has to fulfil the requirements mentioned above. So far, we used the transparent wide gap material N,N,N,N-tetrakis(4-methoxyphenyl)-benzidine (MeO-TPD *) (see Fig. 2) for the p- side as hole transport material. The disadvantages for this material are: (a) morphological instability with $\mathrm{T}_{g}=70^{\circ} \mathrm{C}$, (b) HOMO of $-5.1 \mathrm{eV}$ causes energetic losses due to energetic barriers. Some new promising materials for the pside have been found and will be discussed here. Even for the n- side, ${ }^{10}$ a lack of a suitable transport material present, but it will not be the focus of this paper.

\section{EXPERIMENTAL}

Materials. The semiconducting materials $\mathrm{C}_{60}$ (Kurchatov-Institute Moscow) and zinc phthalocyanine (ZnPc, Alpha Aesar) are used as photovoltaic active materials.

The investigated hole transport materials are:

(1) N,N'-Di(4-(2,2-diphenyl-ethen-1-yl)-phenyl)-N,N'-di(4-methylphenyl-phenyl)benzidine (PV-TPD);

(2) N,N'-Di(4-(2,2-diphenyl-ethen-1-yl)-phenyl)-N,N'-diphenyl-benzidine (PV-TPDoM);

(3) 2,7-Bis[N,N-bis(4-methoxy-phenyl)amino]9,9-spiro-bifluorene (MeO-Spiro-TPD) and

(4) N,N'-diphenyl-N,N'-bis(4'-[N,N-bis(naphth-1-yl)-amino]-biphenyl-4-yl)-benzidine (Di-NPB).

\footnotetext{
*Sensient Imaging Technologies GmbH
} 


\section{hole transport materials}
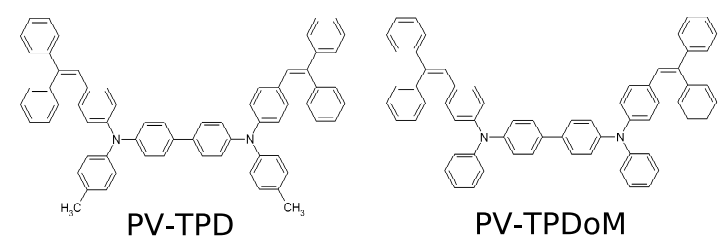

photovoltaic active materials

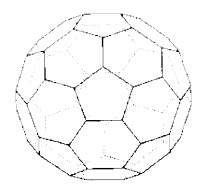

$\mathrm{C} 60$



$\mathrm{ZnPc}$
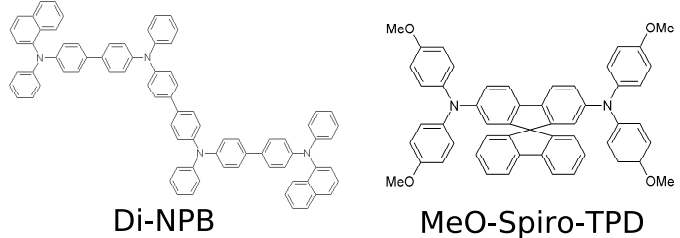

replaced hole transport material

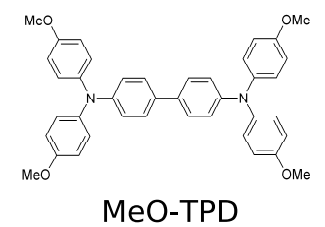

Figure 2. Molecular structures of: the investigated hole transport materials PV-TPD, PV-TPDoM, Di-NPB, MeO-Spiro$\mathrm{TPD}$; photovoltaic active materials $\mathrm{C}_{60}$ and $\mathrm{ZnPc}$; and the morphologically unstable hole transport material MeO-TPD.

All materials are commercially available at Sensient $\mathrm{GmbH}$ and were purified twice by vacuum gradient sublimation $^{11}$ before usage. The molecular structures of the materials are shown in Fig. 2.

For the controlled doping of the hole transport materials the p- dopant (NDP2) of the Novaled AG Dresden was used instead of the 2,3,5,6-tetrafluoro-7,7,8,8-tetracyanoquinodimethan ( $\mathrm{F}_{4}$-TCNQ) due to the better handling. Comparative experiments show that the electronic properties of doped layers are the same for both dopants.

Preparation and Characterisation. All samples were prepared on pre-cleaned ITO substrates (Thin Film Devices Inc., $\leq 30 \mathrm{Ohm} /$ square) for devices and quartz glass for optical investigations. The cleaning procedure in the ultrasonic bath was in the following order: extran, deionised water, aceton, ethanol, and isopropanol. Cleaned substrates were coated against contamination with the polymer optic-clean (LOT-Oriel GmbH) and removed just before lock in vacuum.

The thermal depositions with a rate of $0.5 \AA$ were processed in high vacuum $\left(<2 \cdot 10^{-6} \mathrm{~Pa}\right)$ under ambient conditions. The doped transport layers (matrix and dopant) co-deposition and the depositions rates of each source were controlled by an independent oscillating crystal and monitor (Leybold Inficon Inc. Deposition Monitor $\mathrm{XTM} / 2$ ). I-V characteristics of the device were measured by a computer-controlled program connected to a Keithley Source Measure Unit (SMU236). To prevent degradation, all devices were only handled in a glove box which is directly connected to the vacuum system. To simulated the global AM 1.5 spectrum a sun simulator (SOL 1200, Hoenle AG) was installed below the glove box. The light intensity $\mathrm{I}_{0}$ for the sample position was measured by a silicon reference diode (Fraunhofer Institut für solare Energiesysteme, Freiburg (Germany)). An possible spectral mismatch between the simulated and the AM 1.5 sun spectrum or between the spectral response of reference cell and test cell is not taking into account here, because only comparison of the different transparent materials should be done.

The active area of the devices is given by the overlap of the ITO and the gold contacts and is about 3-4 $\mathrm{mm}^{2}$. The optical properties e.g. absorption and reflection of the transport materials were determined on a $20 \mathrm{~nm}$ neat layer on a quartz glass and analysed with the spectrometer Shimadzu (MPC-3100). The measurements were done ex-situ under ambient conditions.

Solar cells are exposed to high operating temperatures due to the strong irradiation thermal and morphological stability up to $85^{\circ} \mathrm{C}$ is important, here focus on the transport materials. To obtain the glass transition temperature it was carried out a DSC (differential scanning calorimetry, Mettler Toledo DSC 823) measurement which was made available Heliatek $\mathrm{GmbH}^{b}$. Two crucibles, one filled with material, the other as empty reference, were exposed to an initial temperature of $50^{\circ} \mathrm{C}$ and then continuously increased up to $400^{\circ} \mathrm{C}$. Consequently it comes 
to changes in temperatures $\Delta \mathrm{T}$ in comparison to the reference sample due to the thermal capacity of the sample and to exothermal or endothermal processes, changes in phase (e.g. melting and evaporation). Endothermal peaks were detected.

HOMO levels (highest occupied molecular orbital) were measured by cyclic voltammetry (Leibniz-Institut für Festkörper- und Werkstoffforschung Dresden, Germany) and compared to a $\mathrm{C}_{60}$-m-i-p-diode with the controlling interface $\mathrm{C}_{60}$ /i-HTL . All measured CV potentials were related to the redox system Ferrocen/Ferrocinium (E vs.

$\mathrm{Fc} / \mathrm{Fc}+)$. The electrolyte Tetrabutylammoniumhexafluorophosphat $\left(\mathrm{N}^{n} \mathrm{Bu}_{4}\right) \mathrm{PF}_{6}$ was used in a concentration of $0.1 \mathrm{~mol} / \mathrm{l}$.

The lateral conductivity of neat and doped layers were measured between two ITO stripes with an applied voltage from $0 \mathrm{~V}$ up to $10 \mathrm{~V}$. This method is valid for the following reasons: (a) the low feed cable resistances in comparison to the high resistance of the organic films are negligible; (b) limiting charge carrier effect can be excluded due to precisely linear behaviour of the I-V characteristic.

The hole mobility of the hole transport layer (HTL) measured in single carrier devices. For this purpose a hole-only device with the following device structure was made and measured accordingly: ITO/NDP2/p-HTL/iHTL/p-HTL/Au.

\section{RESULTS}

\subsection{Characterisation of the hole transport materials}

\subsubsection{Optical properties of the hole transport materials}

Any absorption in the visible range of light or where the active materials absorb is undesirable for transport materials. Fig. 3(a) shows that the strongest absorption is taking place below $400 \mathrm{~nm}$ and therefore at the edge of the visible range of light. Hence the materials can be indicate as transparent will not decrease the efficiency of the solar cell noticeably. Considering the molecular structure of the hole transport materials the shifts between the absorption peaks can be explained as follows: with enlargement of the $\pi$-electron system, a red shift normally occurs. In our case, the small molecule MeO-Spiro-TPD is forced due to the spiro-link compound to an planarised configuration and has therefore a significant red shift. The weak intermolecular binding of the Di-NPB between the bi-phenyl rings is strong non-planar as a general rule. Thus smaller $\pi$-electron systems appear contrary to the PV-TPDs strong planar and therefore rather strong conjugated phenylene-vinylene group in the blue shifted regime.

The reflection peaks (see Fig. 3(b)) are located around $400 \mathrm{~nm}$ and do not relevantly affect the active absorption regime from 450-650 nm. Obviously PV-TPD and PV-TPDoM have the highest reflection values. Thus can negatively influence the generation of the photo current of the $\mathrm{C}_{60}$. Unfortunately, this can not be evidenced owing to non-optimised cell structure.

The optical gap $\mathrm{E}_{G}^{\text {opt }}$ can be derived from the band edge (absorption spectra) at low energies and is given by

$$
E_{G}^{o p t}=\frac{h c}{\lambda_{\max }} .
$$

The calculation gives optical band gaps which are reduced by the absolute value of the exciton binding energy in comparison to the HOMO/LUMO-gap (electronic band gap) to $2.77 \mathrm{eV}, 2.74 \mathrm{eV}, 2.89$, and $2.87 \mathrm{eV}$ for the materials PV-TPD, PV-TPDoM, Di-NPB and MeO-Spiro-TPD respectively. The materials are all wide gap materials which do not absorb in the visible range of the solar spectrum and therefore are suitable as transparent transport layers as mentioned above.

\subsubsection{Differential scanning calorimetry}

Under irradiation the solar cells are exposed to operation temperatures which can reach over $85^{\circ} \mathrm{C}$ and affect the organic molecules. Changes in layer morphology and molecular structure affect life time and efficiency of the devices.

The changes in the molecules can be determined with the differential scanning calorimetry (DSC) method.

The first observed endothermal peak for each material defines the glass transition temperature $\mathrm{T}_{g}$ respectively. The measured $\mathrm{T}_{g}$ via Mettler Toledo (DSC 823) are shown in the table 1. All materials show a glass transition 


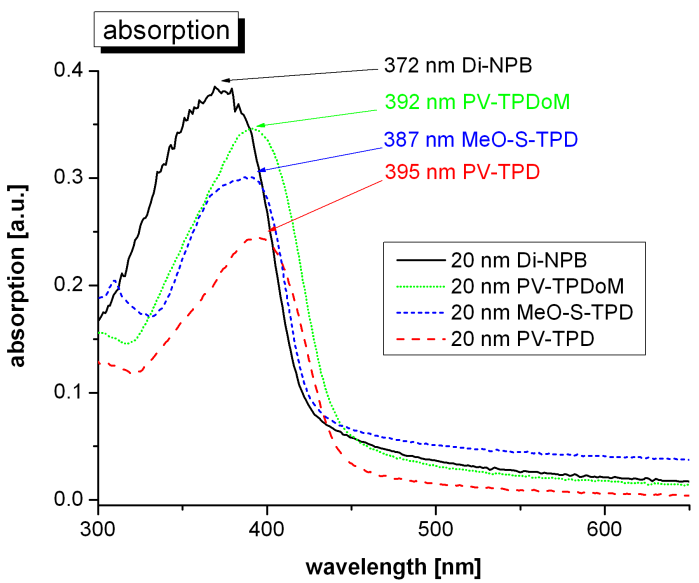

(a) Absorption peaks of the hole transport layers.

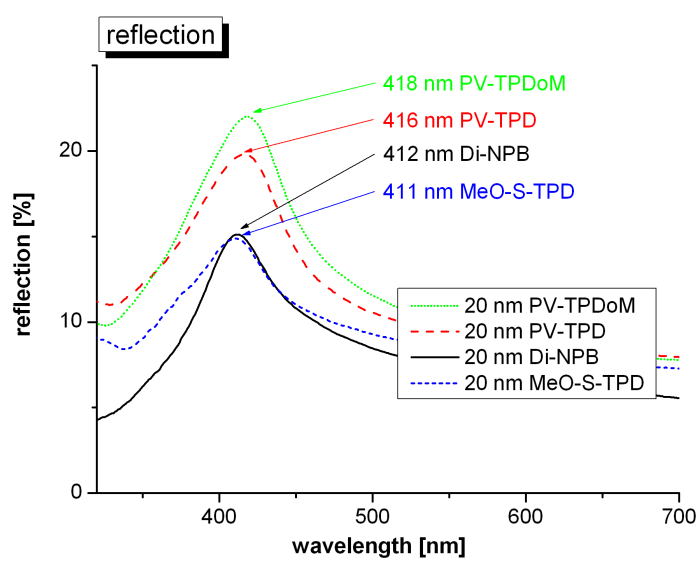

(b) Reflection peaks of the hole transport layers.

Figure 3. a) Absorption spectra of the different $20 \mathrm{~nm}$ thick transport materials b) reflection spectra of the different 20 nm thick transport materials.

Table 1. Glass transition temperatures $\mathrm{T}_{g}$ for PV-TPD, PV-TPDoM, Di-NPB and MeO-Spiro-TPD, respectively.

\begin{tabular}{|c|c|c|c|c|}
\hline & PV-TPD & PV-TPDoM & Di-NPB & MeO-Spiro-TPD \\
\hline $\mathrm{T}_{g}\left[{ }^{\circ} \mathrm{C}\right]$ & 118.2 & 117.5 & 157.8 & 115.7 \\
\hline
\end{tabular}

temperature above the required limit and therefore they are suitable for organic solar cells. The MeO-Spiro-TPD has an enhanced morphologically stability in comparison to the almost equal molecule $\mathrm{MeO}-\mathrm{TPD}\left(\mathrm{T}_{g}=70^{\circ} \mathrm{C}\right)$. The additional spiro link leads to a more stabilised MeO-Spiro-TPD molecule. ${ }^{12}$ Di-NPB has a notably high glass transition temperature of $157.8^{\circ} \mathrm{C}$ and therefore is supposed to be morphologically stable under operation conditions of solar cells.

\subsubsection{Lateral conductivity}

To enhance the charge carrier density and thus the conductivity, the transport layers are molecular doped using the co-deposition. In the case of isotropic films, this lateral conductivity corresponds to the conductivity perpendicular to the substrate. The doped layers of a thickness of $50 \mathrm{~nm}$ were deposited on a pre-cleaned three strip ITO structured substrate and were measured under nitrogen-atmosphere condition.

Different conductivities were achieved by varying the doping ratios of the transport materials. A significant

Table 2. Conductivity of the hole transport materials for a doping ratio of 1:30.

\begin{tabular}{|c|c|c|c|c|}
\hline & PV-TPD & PV-TPDoM & Di-NPB & MeO-Spiro-TPD \\
\hline$\sigma_{1: 30}[\mathrm{~S} / \mathrm{cm}]$ & $4.43 \cdot 10^{-6}$ & $4.71 \cdot 10^{-6}$ & $5.38 \cdot 10^{-6}$ & $3.45 \cdot 10^{-5}$ \\
\hline
\end{tabular}

enhancement of the conductivity with increasing the doping ratio from 1:60 to 1:15 was observe. The required conductivities for transport layers greater than $1 \cdot 10^{-6} \mathrm{~S} / \mathrm{cm}$ were reached with a molecular doping ratio of $1: 30$ (NDP2:HTM), as shown in table 2. Unfortunately, it was not possible to dope the transparent wide gap material 4P-TPD with a HOMO level at $-5.55 \mathrm{eV}$. 


\subsubsection{Hole mobility}

The hole mobility is an important parameter which has to be taken into account and can determined by using hole-only devices.

The measurement is only done for the most promising material Di-NPB. The device structure is the following:

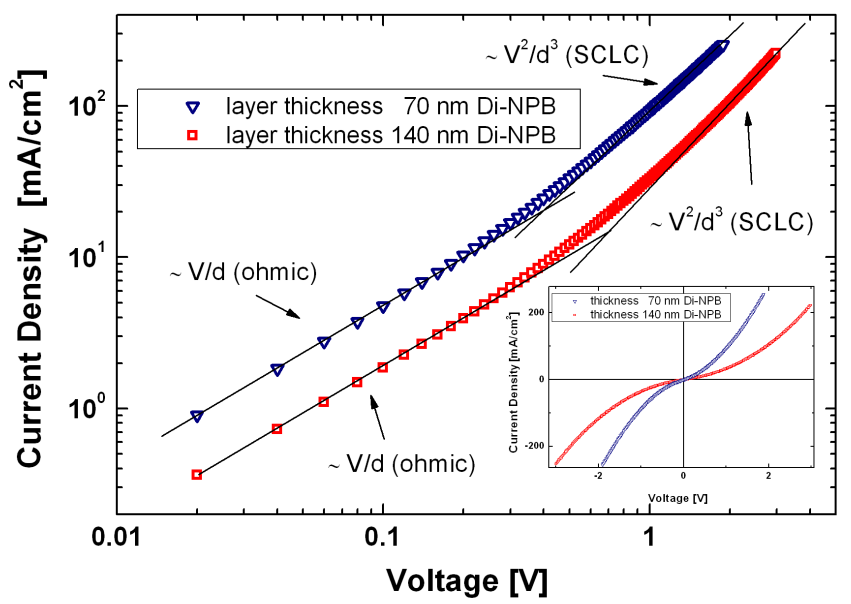

Figure 4. Hole-only device of Di-NPB with the following device structure:

ITO/NDP2(1nm)/p-Di-NPB(28nm;1:15)/Di-NPB(70/140nm)/p-Di-NPB(28nm;1:15)/p-ZnPc(10nm;1:10)/Au, varied intrinsic layer of 70 and $140 \mathrm{~nm}$.

ITO/NDP2(1nm)/p-Di-NPB(28nm;1:15)/Di-NPB(70/140nm)/p-Di-NPB(28nm;1:15)/p-ZnPc(10nm;1:40)/Au. The additional NDP2 and p-ZnPc layers were inserted to provide ohmic contacts and exclude limitations of charge carrier injection.

At a given voltage the space charge limited current (SCLC) sets in and the slope in the semilogarithmic plot is two as shown in the graph 4. Because of the symmetric device structure and symmetric charge carrier injection the I-V characteristic (see inset in Fig. 4) shows on that account also a symmetric behaviour. In the region of space charge limited current, the formula

$$
J=\frac{9}{8} \cdot \epsilon_{r} \cdot \epsilon_{0} \cdot \mu_{h} \cdot \frac{V^{2}}{d^{3}}
$$

can be used to calculate the hole mobility from the voltage $\mathrm{V}$, current density $\mathrm{J}$, and intrinsic layer thickness d. Using $\epsilon_{r}=3.6$ leads to $\mu_{h}=1.9 \cdot 10^{-4} \mathrm{~cm}^{2} / \mathrm{Vs}$. To determine if the relation of free and trapped charge carriers is voltage dependent the $\frac{U^{2}}{d^{3}}$ behaviour is considered. Hence the intrinsic layer of the device was varied to 70 and $140 \mathrm{~nm}$ thickness and no deviation was observed:

we did not obtain any voltage dependence of free and trapped charge carriers and in the region of space charge limited current of the I-V curve, the slope is two as required.

\subsubsection{Cyclic voltammetry and $\mathrm{C}_{60}-\mathrm{m}$-i-p-diode}

A excellent alignment of the HOMO levels at interface avoid or minimise energetic losses due to band barriers. The used $\mathrm{C}_{60}-\mathrm{m}$-i-p-diode to determine the HOMO levels of the transport materials has the following structure: ITO $/ \mathrm{C}_{60}(15 \mathrm{~nm}) / \mathrm{i}-\mathrm{HTL}(42 \mathrm{~nm}) / \mathrm{p}-\mathrm{HTL}(70 \mathrm{~nm}) / \mathrm{p}-\mathrm{ZnPc}(10 \mathrm{~nm}) / \mathrm{Au}$. The measured I-V characteristics of the devices and the solar cell parameters are shown in Fig. 5(a),5(b). The open circuit voltage correlates, however, with the difference of the LUMO $\left(\mathrm{C}_{60}\right)$ and the HOMO (HTL), more precisely with the quasi-Fermi-levels of the 
transport layers. Unfortunately, the origin of $\mathrm{V}_{o c}$ is not completely understood so far. The $\mathrm{C}_{60}$ has an electron affinity of $-4.0 \mathrm{eV}$ and is a fixed part of the cell. Only the hole transport materials are exchanged. The open circuit voltage $\mathrm{V}_{o c}=0.76 \mathrm{~V}$ of the $\mathrm{C}_{60}-\mathrm{m}$-i-p-diode with Di-NPB is qualified with the UPS measurement value of neat Di-NPB with an obtained HOMO level of $-5.40 \mathrm{eV}$. All given HOMO levels of the residual transport materials are given in relation to the $\mathrm{HOMO} / \mathrm{V}_{o c}$ of Di-NPB. The estimated HOMO levels which are in relation to the $\mathrm{V}_{o c}$ values are shown in table 3 . To verify the estimated values using the $\mathrm{C}_{60}-\mathrm{m}$-i-p-diode, the method of cyclic

Table $3 . \mathrm{V}_{o c}$ and estimated HOMO levels in relation to the UPS measurement of Di-NPB.

\begin{tabular}{|c|c|c|c|c|}
\hline & PV-TPD & PV-TPDoM & Di-NPB & MeO-Spiro-TPD \\
\hline $\mathrm{V}_{o c}[\mathrm{~V}]$ & 0.77 & 0.82 & 0.76 & 0.42 \\
\hline $\mathrm{HOMO}_{C_{60}-\text { mip-diode }}[\mathrm{eV}]$ & $\approx-5.41$ & $\approx-5.46$ & $\approx-5.40$ & $\approx-5.05$ \\
\hline $\mathrm{HOMO}_{C V}[\mathrm{eV}]$ & $\approx-5.04$ & $\approx-5.11$ & $\approx-5.07$ & $\approx-4.86$ \\
\hline
\end{tabular}

voltammetry was carried out. The measured HOMO levels are also shown in Table 3. Obviously, a significant difference in the HOMO levels between the two methods occurs. The absolute differences of the HOMO levels of the materials between the two analysis methods are from 0.33 to $0.36 \mathrm{eV}$ except of MeO-Spiro-TPD with 0.2 $\mathrm{eV}$. One explanation is that the $\mathrm{V}_{o c}=0.42 \mathrm{~V}$ determined for the MeO-Spiro-TPD sample is decreased due to recombination effects. If one consider the devices structures and the measured solar cell parameters for this cell (see Fig. 5(a),5(b)), one can assume that the direct recombination path between $\mathrm{C}_{60}$ and i-MeO-Spiro-TPD is responsible for the fermi-level bending and reduction of $\mathrm{V}_{o c}$. The decreased fill factor and enhanced saturation current (relation $\mathrm{j}(-1 \mathrm{~V}) / \mathrm{j}_{s c}$ ) evidence this assumption of elevated recombination.

The absolute values of the CV-measurement are apparently too low, but the relative values are in good agreement with the values estimated with the $\mathrm{C}_{60}-\mathrm{m}$-i-p-diode. Nevertheless, the HOMO-level estimation is a fast and promising method, but only for samples with very low recombination effects.

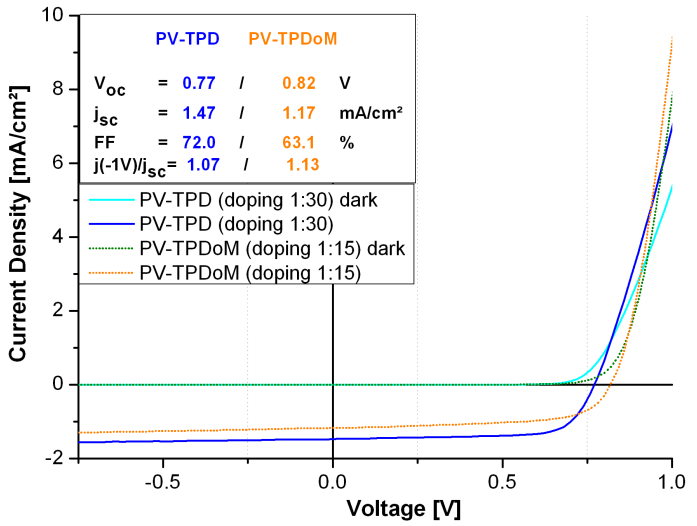

(a)

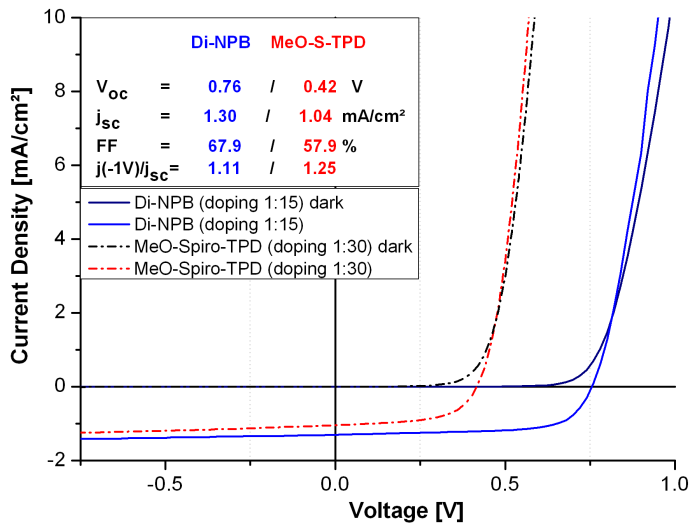

(b)

Figure 5. I-V characteristics of the $\mathrm{C}_{60}-\mathrm{m}-\mathrm{i}$-p-diode with the device structure: $\mathrm{ITO} / \mathrm{C}_{60}(5 \mathrm{~nm}) / \mathrm{C}_{60}: \mathrm{ZnPc}(2: 1 ; 30 \mathrm{~nm}) / \mathrm{i}-$ $\mathrm{HTL}(5 \mathrm{~nm}) / \mathrm{p}-\mathrm{HTL}(1: \mathrm{X} ; 56 \mathrm{~nm}) / \mathrm{p}-\mathrm{ZnPc}(1: 25 ; 10 \mathrm{~nm}) / \mathrm{Au}$; estimation of the HOMO levels by comparison of the $\mathrm{V}_{o c}$. a) for the hole transport material PV-TPD and PV-TPDoM b) for the hole transport material Di-NPB and MeO-Spiro-TPD.

\subsection{Organic bulk heterojunction $\mathrm{C}_{60}: \mathrm{ZnPc}$ solar cell}

P-i-n solar cells with the well established blend donor:acceptor system made of $\mathrm{ZnPc:}_{60}$ are the standard configuration and used here for determining the most promising hole transport material. 
The bulk heterojunction has the following structure:

ITO $/ \mathrm{C}_{60}(5 \mathrm{~nm}) / \mathrm{C}_{60}: \operatorname{ZnPc}(2: 1 ; 30 \mathrm{~nm}) / \mathrm{i}-\mathrm{HTL}(5 \mathrm{~nm}) / \mathrm{p}-\mathrm{HTL}(1: \mathrm{X} ; 56 \mathrm{~nm}) / \mathrm{p}-\mathrm{ZnPc}(1: 25 ; 10 \mathrm{~nm}) / \mathrm{Au}$ and is not optimised for the optical field distribution. Nevertheless, all samples are comparable due to the same device thicknesses. As shown in Figure 6, the best power conversion efficiency of $\eta_{\text {eff }}=2.73 \%$ is obtained with the hole transport material Di-NPB. Also for the sample with PV-TPD were suitable values measured, despite some energetic losses. Concerning the sample made with PV-TPDoM, a bad I-V characteristic occurs due to the large energy barrier from the blend layer $\mathrm{C}_{60}: \mathrm{ZnPc}$ to the deep lying hole transport layer. For the generated free charge carriers it is difficult to overcome this energetic barrier and accumulate at the hole transport layer interface. Therefore an enhanced saturation factor of 1.37 , decreased fill factor of $25.7 \%$, and lower $\mathrm{V}_{\text {oc }}$ are attributed to recombination effects due to the energetic barrier and accumulation. In backward direction an extra electrical field is provided to the free charge carriers and thus able to overcome easier the energetic barrier. However, it is obvious that the solar cell with Di-NPB as hole transport material leads to best values and power conversion efficiency. All calculated power conversion efficiencies are without correction for spectral mismatch. The energy level alignment between the hole transport layer Di-NPB and the photoactive layer seems to be efficient for this kind of absorber system.

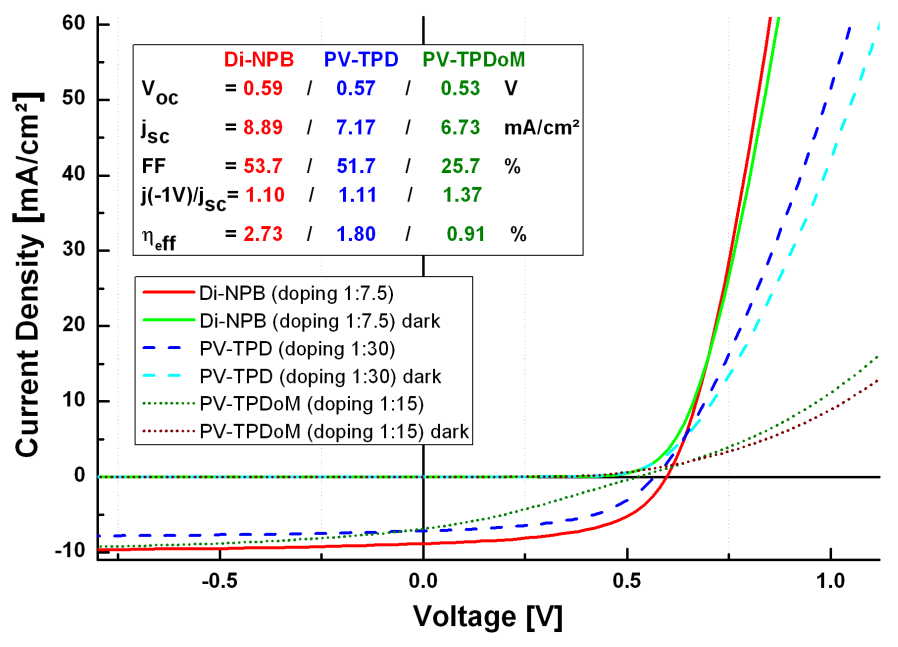

Figure 6. Standard bulk heterojuntion $\mathrm{C}_{60}: \mathrm{ZnPc}$ solar cell with the following device structure: ITO/C 60 (5nm)/ $\mathrm{C}_{60}: \operatorname{ZnPc}(2: 1 ; 30 \mathrm{~nm}) / \mathrm{i}-\mathrm{HTL}(5 \mathrm{~nm}) / \mathrm{p}-\mathrm{HTL}(1: \mathrm{X} ; 56 \mathrm{~nm}) / \mathrm{p}-\mathrm{ZnPc}(1: 25 ; 10 \mathrm{~nm}) / \mathrm{Au}$.

\section{CONCLUSION}

We have shown in this work that the required properties for a transparent hole transport material could be fulfilled. First, the transport materials absorb below $400 \mathrm{~nm}$ which is outside the visible range of light, and thus are transparent. Due to the low absorption losses, the layer thickness can be varied to optimise the optical field distribution. Furthermore, it is shown that the optical gap is larger than $2.7 \mathrm{eV}$ for all hole transport materials. These so called "wide gap" materials have positive effects as efficient exciton- and electron blockers.

The morphological stability for all investigated hole transport materials is investigated by the DSC method determining the glass transition temperature $\mathrm{T}_{g}$. Di-NPB with a $\mathrm{T}_{g}$ of $157.8^{\circ} \mathrm{C}$ is the most favourable material concerning morphological stability under operating conditions.

The required conductivity of $\sigma>1 \cdot 10^{-6} \mathrm{~S} / \mathrm{cm}$ to obtain negligible losses for layer thicknesses in the order of 100 $\mathrm{nm}$ is reached with the molecular doping ration of 1:30 with the dopant NDP2 for all materials. The obtained conductivities are larger than $4 \cdot 4 \cdot 10^{-6} \mathrm{~S} / \mathrm{cm}$. Due to the fact that conductivities have to be as high as possible 
and the conductivity directly depends on the the mobility, a high hole mobility is desirable. The measured hole mobility by using a hole only device is high enough with $1.9 \cdot 10^{-4} \mathrm{~cm}^{2} / \mathrm{Vs}$.

The energy levels were determined by cyclic voltammetry and compared to a $\mathrm{C}_{60}-\mathrm{m}$-i-p-diode. The estimated values for the $\mathrm{HOMO}$ levels in the $\mathrm{C}_{60}-\mathrm{m}$-i-p-diode and verified with cyclic voltammetry are $-5.41 \mathrm{eV},-5.46 \mathrm{eV}$, -5.40, and -5.05 eV for PV-TPD, PV-TPDoM, Di-NPB, and MeO-Spiro-TPD, respectively. Except of MeOSpiro-TPD, all materials have a deep lying HOMO level and do not lead to energy losses due to barriers. We also note that the estimation for the HOMO levels is only permitted for $\mathrm{C}_{60}-\mathrm{m}$-i-p-diode with very low recombination effects.

Finally, heterojunction $\mathrm{C}_{60}: \mathrm{ZnPc}$ solar cells were made to test the combination of the photo active absorber system with the hole transport materials. The most promising material Di-NPB with a high $\mathrm{T}_{g}$ and high hole mobility leads with this device structure to a power conversion efficiency of $2.73 \%$ (without spectral mismatch), although the cell structure is not optimised for high photo current. We conclude that Di-NPB has notably convinced with the optical and electrical properties.

\section{ACKNOWLEDGMENTS}

We would like to thank Dirk Hildebrandt for providing and support of the glass transition temperature measurements. The current work is supported by the Bundesministerium für Bildung und Forschung in the framework of the InnoProfile project (03IP602).

\section{REFERENCES}

[1] S. Shaheen, R. Radspinner, N. Peyghambarian, and G. Jabbour, "Fabrication of bulk heterojunction plastic solar cells by screen printing," Applied Physics Letters 79, p. 2996, 2001.

[2] C. Lungenschmied, G. Dennler, H. Neugebauer, S. N. Sariciftci, M. Glatthaar, T. Meyer, and A. Meyer, "Flexible, long-lived, large-area, organic solar cells," Solar Energy Materials And Solar Cells 91, p. 379, 2007.

[3] C. Tang, "Two-layer organic photovoltaic cell," Applied Physics Letters 48, p. 183, 1986.

[4] G. Dennler, C. Lungenschmied, H. Neugebauer, N. S. Sariciftci, M. Latreche, G. Czeremuszkin, and M. R. Wertheimer, "A new encapsulation solution for flexible organic solar cells," Thin Solid Films 511, p. 349, 2006.

[5] K. Walzer, B. Maennig, M. Pfeiffer, and K. Leo, "Highly efficient organic devices based on electrically doped transport layers," Chemical Reviews 107, p. 1233, 2007.

[6] J. Drechsel, B. Maennig, F. Kozlowski, D. Gebeyehu, A. Werner, M. Koch, K. Leo, and M. Pfeiffer, "High efficiency organic solar cells based on single or multiple pin structures," Thin Solid Films 451-452, p. 515, 2004.

[7] M. Pfeiffer, A. Beyer, T. Fritz, and K. Leo, "Controlled doping of phthalocyanine layers by cosublimation with acceptor molecules: A systematic seebeck and conductivity study," Applied Physics Letters 73, p. 3202, 1998.

[8] B. Maennig, M. Pfeiffer, A. Nollau, X. Zhou, P. Simon, and K. Leo, "Controlled p-doping of polycrystalline and amorphous organic layers: Self-consistent description of conductivity and field-effect mobility by a microscopic percolation model," Physical Review B 64, p. 195, 2001.

[9] J. Drechsel, B. Maennig, F. Kozlowski, M. Pfeiffer, K. Leo, and H. Hoppe, "Efficient organic solar cells based on a double p-i-n architecture using doped wide-gap transport layers," Applied Physics Letters 86, p. 244102, 2005.

[10] C. K. Chan, E. G. Kim, J. L. Bredas, and A. Kahn, "Molecular n-type doping of 1,4,5,8-naphthalene tetracarboxylic dianhydride by pyronin b studied using direct and inverse photoelectron spectroscopies," Advanced Functional Materials 16, p. 831, 2006.

[11] J. Drechsel, A. Petrich, M. Koch, S. Pfützner, R. Meerheim, S. Scholz, J. Drechsel, K. Walzer, M. Pfeiffer, and K. Leo, "Influence of material purification by vacuum sublimation on organic optoelectronic device performance," SID Symposium Digest of Technical Papers 37, p. 1692, 2006.

[12] Y. Shirota and H. Kageyama, "Charge carrier transporting molecular materials and their applications in devices," Chemical Reviews 107, p. 953, 2007. 